\title{
Abnormal pulse wave velocity in bicuspid aortic valve: comparison to trileaflet aortic valve and the impact of aortic regurgitation Prabhakar Rajiah*, Randolph Setser and Scott D Flamm
}

\author{
Address: Cleveland Clinic Foundation, Cleveland, OH, USA \\ * Corresponding author
}

from 13th Annual SCMR Scientific Sessions

Phoenix, AZ, USA. 2I-24 January 2010

Published: 21 January 2010

Journal of Cardiovascular Magnetic Resonance 2010, I2(Suppl I):O43 doi:I0.I I86/I532-429X-I2-SI-O43

This abstract is available from: http://jcmr-online.com/content/I2/SI/O43

(C) 2010 Rajiah et al; licensee BioMed Central Ltd.

\section{Introduction}

Abnormal aortic stiffness implies an unfavorable prognosis in a variety of aortic diseases, and is considered an emerging biomarker for cardiovascular disease. In bicuspid aortic valve (BAV), aortic stiffness can be elevated as a result of intrinsic aortopathy, as well as geometrical, morphological and functional abnormalities. Aortic regurgitation (AR) is associated with $\mathrm{LV}$ dysfunction in approximately $4 \%$ of patients per year. It has been found that loss of vascular elasticity in patients with AR hastens the development of symptoms, as typically aortic regurgitation is compensated for by increased systolic volume, which is then further accommodated by compliant arteries.

\section{Purpose}

The aim of this study was to assess aortic stiffness by pulse wave velocity (PWV) measurements from velocity encoded magnetic resonance (VENC-MRI) in patients with BAV, and determine if a gradient of PWV abnormalities exists relative to the degree of aortic regurgitation in patients with BAV. And secondarily to compare these abnormalities in patients with $A R$, but trileaflet valves along with normal controls.

\section{Methods}

VENC-MRI was performed in 100 patients with BAV, 100 patients with trileaflet valve with dilated aorta, and 40 normal control subjects. BAV and trileaflet groups were aortic size matched. AR was graded based on echocardiography on a 0 -4 scale (0-none, 1-mild, 2-moderate, 3-moderatesevere, 4-severe), with 20 patients each per grade.
PWV was determined between the mid ascending and descending thoracic aorta.

\section{Results}

The mean aortic sinus diameter was $3.9 \pm 0.9 \mathrm{~cm}$ in BAV, $3.7 \pm 0.8 \mathrm{~cm}$ in trileaflet valve, and $3.0 \pm 0.2 \mathrm{~cm}$ in normal controls. Hypertension (HTN) was higher in the trileaflet group than the BAV ( $62 \%$ vs $35 \%, \mathrm{p}<0.001)$. PWV was significantly elevated in both the BAV and trileaflet patients, as compared to controls $(8.1 \pm 6.3 \mathrm{~m} / \mathrm{s}, 8.1 \pm 4.5$ $\mathrm{m} / \mathrm{s}$ vs $4.0 \pm 1.1 \mathrm{~m} / \mathrm{s}, \mathrm{p}<0.001)$. PWV in different grades of AR in BAV and trileaflet valve were not significantly different, except for Grade 1 regurgitation patients where there was a significantly elevated PWV in the BAV patients compared to the trileaflet Grade 1 group $(\mathrm{p}<0.001)$.

\section{Conclusion}

There are minor differences in aortic stiffness between grades of AR in BAV and trileaflet valves. However, controlling for aortic size there is no statistically significant difference between the groups, making uncertain the etiology for abnormal aortic stiffness. Intrinsic aortopathy in BAV and increased HTN in trileaflet valve group may have comparable effects and warrant further research. 